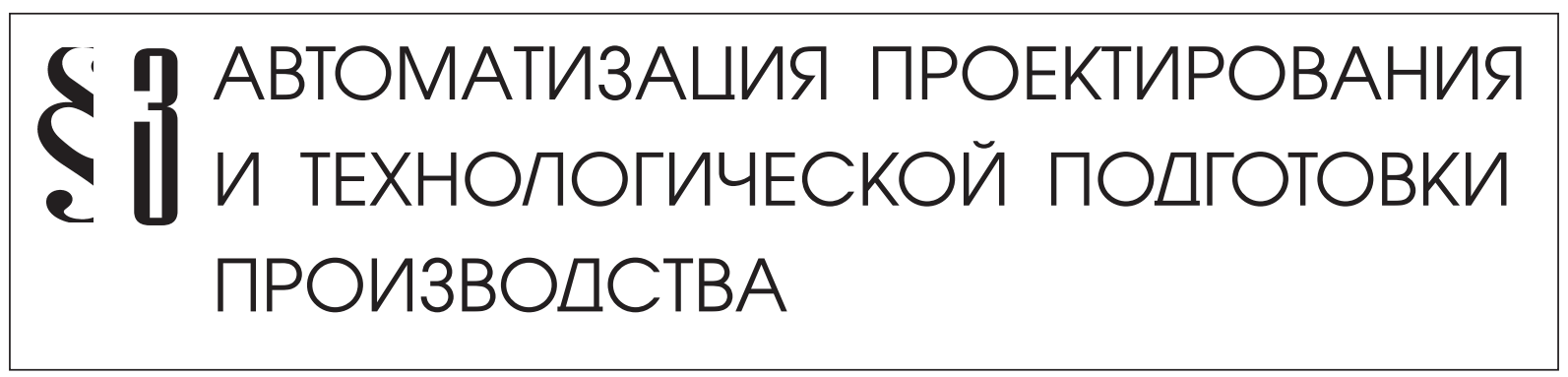

Гусев Д.В., Климов Р.С.

\title{
ПРОГРАММНЫЙ КОМПЛЕКС АПРИОРНОГО ОЦЕНИВАНИЯ ПОКАЗАТЕЛЕЙ КАЧЕСТВА ПРОФЕССИОНАЛЬНОЙ ДЕЯТЕЛЬНОСТИ ОПЕРАТОРА ЭРГАТИЧЕСКОЙ СИСТЕМЫ
}

Аннотация: Применение структурных (структурно-алгоритмических) методов описания трудовой деятельности оператора эргатической системы, описывающих ее с точки зрения ее надежности и эфрфективности, позволяет структурировать деятельность, вскрывать логические механизмы процессов переработки информации и принятия решений оператором, и определять последовательно-параллельный характер выполнения отдельных операций. Однако решение указанных задач, особенно в масштабе времени, близком к реальному, требует большого объема вычислений. Поэтому автоматизация априорного оченивания показателей качества деятельности операторов эргатических систем на основе структурных методов является важной практической задачей. Методология исследования объединяет методы программной инженерии, эргономики, теории вероятностей, математической статистики, теории надежности, объектно-ориентированного программирования. Разработанный программный комплекс априорного оченивания показателей качества деятельности операторов эргатической системы на основе структурного метода позволяет автоматизированно определить минимально допустимое время выполнения оператором (экипажем) программной единицы деятельности, важное для получения оценки потенциальной эффективности эргатической системы в любых условиях ее эксплуатации.

Ключевые слова: проектирование эргатических систем, качество деятельности оператора, моделирование трудового прочесса, моделирование деятельности, структурный метод, эргономика, инженерная психология, программная инженерия, оченивание качества деятельности, программная единица деятельности

Abstract: The use of structural (structural and algorithmic) methods of describing the work of operator of ergatic system, describing it in terms of its reliability and efficiency, allows to structure 
activities, to reveal the logical mechanisms of information processing and decision making and determine the serial-parallel nature of individual operations execution. However, the solution of these problems, especially in-near-real-time requires large amount of computation. Therefore, automation of a priori estimation of indicators of quality of professional work of an operator of ergatic system using structural methods is an important practical task. The research methodology combines the methods of software engineering, ergonomics, probability theory, mathematical statistics, reliability theory, object-oriented programming. The developed software system for a priori estimation of indicators of quality of professional work of an operator of ergatic system based on structural method allows to automatically determine the minimum acceptable runtime of operator (crew) activity, important for evaluating the potential effectiveness of ergatic system under all conditions of operation.

Keywords: software engineering, engineering psychology, ergonomics, structural method, modeling activities, modeling of the labor process, quality of the operator's activities, design ergatics systems, quality assessment activities, software element of activity

Деятельность человека-оператора системы «человек-машина» (эргатической системы - ЭС) - процесс, осуществляемый оператором для достижения целей, поставленных перед системой [1]. Формализация деятельности оператора, являющегося элементом системы «человек-машина», предполагает в первую очередь моделирование его трудового процесса (профессиональной деятельности) [2-4].

При моделировании необходимо учитывать форму и тип труда (обслуживание технических устройств, ремонт оборудования и т.д.), составляющие трудовой процесс операции или блоки операций, а также влияние на них направленности деятельности, дефицита времени и других факторов, изменяющих психоэмоциональное состояние специалистов [5-7].

Структурные модели трудового процесса отображают деятельность оператора с точки зрения ее надежности и эффективности [8]. Они строятся на основе типовых блоков с известными вероятностными и временными характеристиками, представленными в общем виде на уровне математического ожидания и дисперсии.

Анализ задач, стоящих перед оператором современных образцов эргатических систем, позволяет сделать вывод об эффективности применения структурных (структурноалгоритмических) методов описания трудовой деятельности оператора. Преимущество этих методов заключается в структурировании деятельности, выделении и анализе ее основных элементов [8-10]. Они позволяют вскрывать логические механизмы процессов переработки информации и принятия решений оператором, определяют последовательно-параллельный характер выполнения отдельных операций. Поэтому автоматизация априорного оценивания показателей качества деятельности операторов ЭС на основе структурного метода является важной практической задачей. 


\section{Базовые положения и методика применения структурного метода}

В основу структурного метода А.И.Губинского положен метод алгоритмического описания процессов управления, т.е. всякое управление производится посредством переработки информации, осуществляемой по соответствующим правилам-алгоритмам [8]. Понятие «алгоритм» определяется ГОСТом как совокупность элементарных актов переработки информации, т.е. алгоритм - предписание, определяющее содержание и последовательность действий оператора ЭС.

При использовании структурного метода проблема оценивания качества их деятельности сводится к двум составляющим [11-14]:

описание конкретной деятельности в виде алгоритмов, наборов условий и ограничений;

определение эффективности выполнения человеком-оператором данных алгоритмов и условий по выбранным показателям качества деятельности операторов (КДО).

Принципиальным положением является то, что любая деятельность человека-оператора в ЭС может быть описана трехуровневой структурой, нижний уровень которой представлен операционными единицами, средний - функциональными единицами и высший - программными единицами [15].

В качестве операционных единиц деятельности понимаются элементарные действия как отдельные психофизиологические акты деятельности человека-оператора [16-17].

Совокупность операционных единиц, представляющая собой в структуре деятельности человека функционально-самостоятельный блок операций, составляют функциональную единицу (элементарная операция), а группа или комбинация функциональных единиц, объединенных в технологическом или смысловом отношении в законченную программу, составляет программную единицу (типовая задача).

Разработанный алгоритм применения структурного метода для априорного оценивания показателей качества деятельности операторов эргатической системы представлен на рис. 1.

Блок 1. Выявление на основании анализа методов эксплуатации конкретной ЭС основные, вспомогательные и аварийные режимы работы. Выявление аварийных режимов в отдельную группу обусловлено специфичностью алгоритмов деятельности человекаоператора в этих режимах.

Блок 2. Выделение программных единиц (ПЕ) деятельности через определение задач, решаемых операторами при каждом режиме функционирования ЭС. При этом выявляются задачи, требующие постоянного участия оператора в процессе управления, и задачи, которые оператор выполняет эпизодически.

Рассмотрим подробнее структуру программной единицы деятельности человекаоператора. Любую программную единицу можно представить как

$$
\Pi E=\{<\Phi E>, A, y, C X, \Pi K\},
$$

где $<\Phi E>-$ множество функциональных единиц (ФЕ) деятельности, выполняемых в 
конкретной ПЕ; $A$ - алгоритм выполнения ПЕ как описание порядка выполнения ФЕ; $У$ система условий и ограничений, накладываемых на выполнение оцениваемой операции (требования по безопасности деятельности, правила эксплуатации технических средств и т.д.); $C X$ - специальные характеристики ПЕ, необходимые при выполнении ее в рамках других ПЕ высшего уровня иерархии; ПК - значения показателей качества выполнения этой ПЕ.

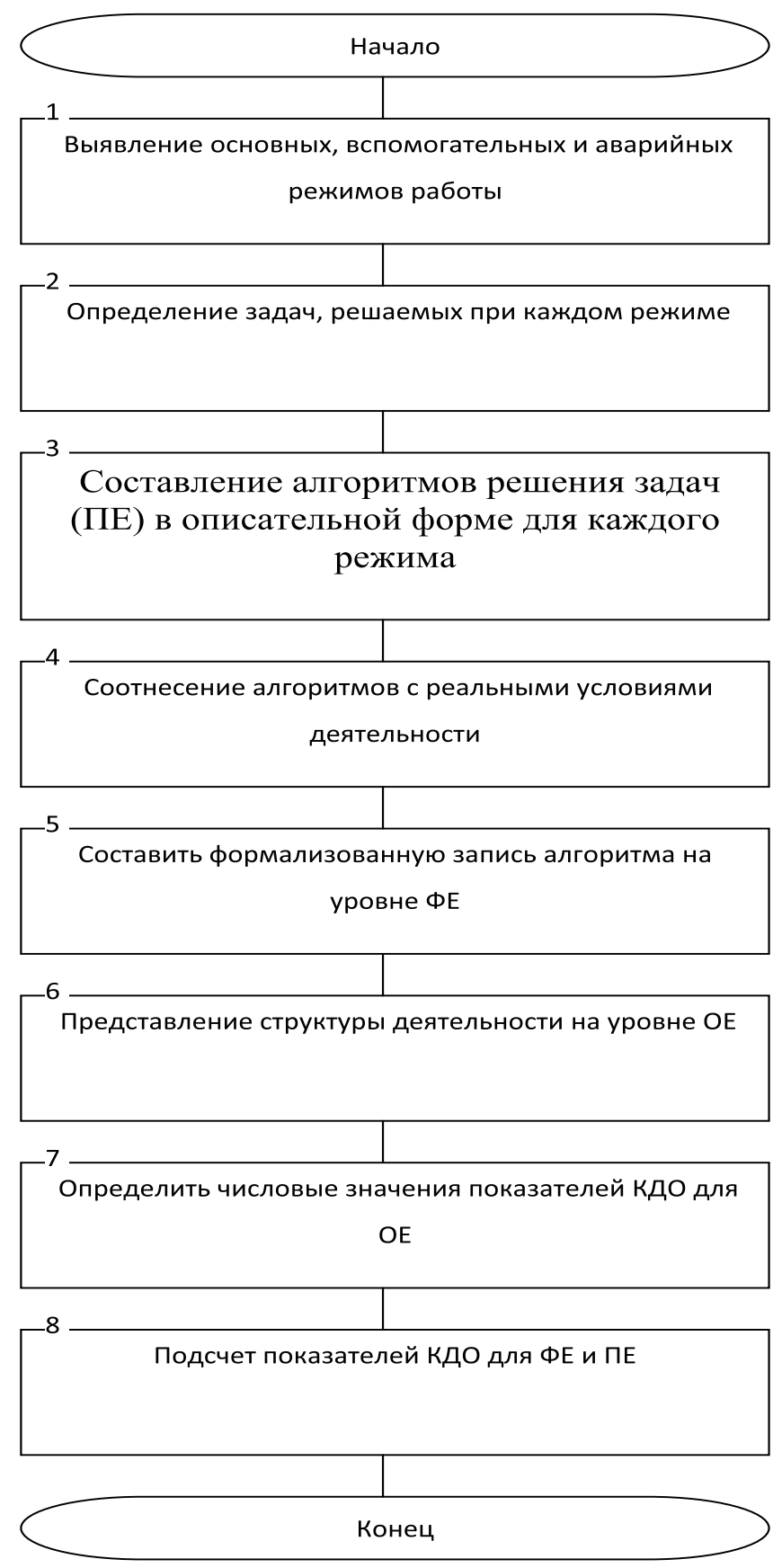

Рисунок 1. Алгоритм априорного оценивания показателей КД0 структурным методом. 
Система СX содержит специальные характеристики используемые при выполнении данной ПЕ в ПЕ высшего уровня иерархии (типовая задача в режиме деятельности): приоритетность выполнения, признак возможности ее прерывания, признак возможности ее последующего довыполнения и так далее.

Система ПК включает совокупность показателей КДО (точность, быстродействие) и показателей эффективности функционирования комплекса технических средств при соблюдении которых ПЕ считается выполненной.

Блок 3. Составление в описательной форме алгоритма деятельности человека-оператора в каждом режиме работы ЭС. При составлении алгоритма необходимо последовательно изложить все действия операторов в зависимости от тех или иныхусловий. При этом дробление деятельности следует производить до уровня операционных единиц (ОЕ).

Блок 4. Соотнесение алгоритмов выполнения задач с условиями деятельности оператора на конкретном рабочем месте. Анализируя размещение органов управления и контроля на рабочем месте и последовательность обращения к ним оператора при выполнении заданного алгоритма, необходимо охарактеризовать работу человека-оператора по выполнению каждого элементарного действия в трехмерном пространстве.

Блок 5. Составить формализованную запись алгоритма на уровне функциональных единиц. При подобной декомпозиции алгоритма выделяют основные функциональные единицы (ФЕ), которые целесообразно классифицировать на основные и вспомогательные (рис. 2) [1, 11].

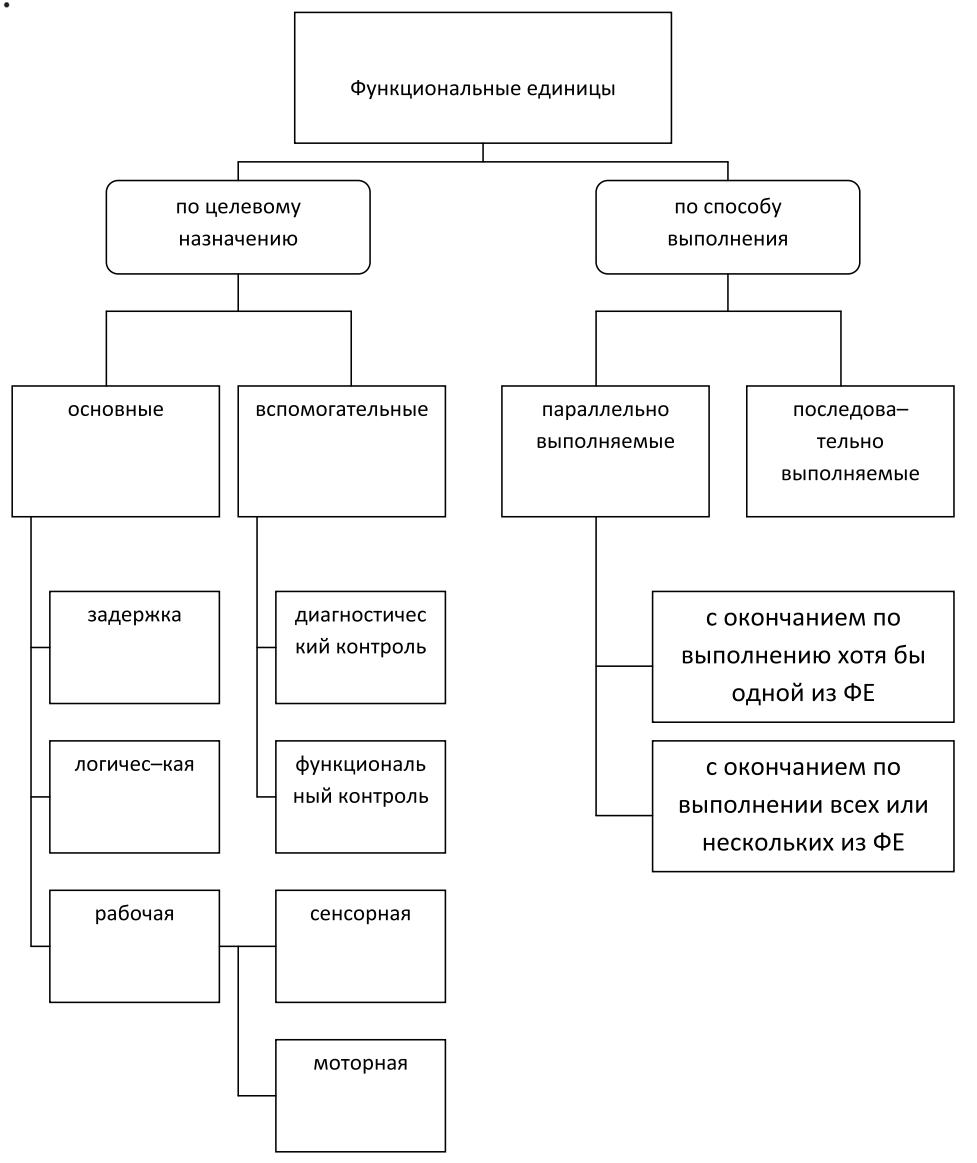

Рисунок 2. Классификация функциональных единиц 
Основные ФЕ представляют собой последовательность оперативных единиц при невыполнении или ошибочном выполнении которых цель, поставленная перед ЭС, не будет достигнута. Вспомогательные ФЕ предназначены для увеличения вероятности безошибочного выполнения операций. Основные ФЕ классифицируются на рабочие (сенсорные и моторные), логические и задержки. Под сенсорной ФЕ понимается совокупность операционных единиц (OE), описывающих функционирование человека, по восприятия (считыванию) информации с помощью зрительного, слухового и других сенсорных входов. Моторная ФЕ - это совокупность ОЕ, предусматривающих реализацию механических и речевых воздействий на органы управления, регулировки и так далее. При декомпозиции деятельности человека-оператора в некоторых случаях целесообразно выделить смешанные сенсомоторные ФЕ.

Логическая ФЕ представляет собой совокупность ОЕ, предусматривающих процесс выбора человеком одной из двух или нескольких альтернатив на основании анализа информации, отображаемой различными средствами.

ФЕ задержка предусматривает предписанное инструкциями ожидание человекомоператором момента, с которого он должен начать или продолжить выполнение своего алгоритма. Эта ФЕ включает $\mathrm{OE}$, необходимые для «переключения» человека на новую операцию, а также время ожидания, пока произойдет обработка необходимых функций используемыми техническими средствами.

ФЕ «функциональный контроль» Включает ОЕ, реализуемые человеком-оператором по установлению правильности выполнения основной ФЕ или нескольких основных ФЕ. В ЭС с одним оператором эта единица означает контроль оператором своей собственной деятельности, а в ЭС с несколькими взаимодействующими операторами - либо самоконтроль, либо контроль деятельности другого, чаще всего подчиненного, оператора.

ФЕ «диагностический контроль» представляет собой совокупность ОЕ по установлению работоспособности технических средств, с которыми этот специалист взаимодействует при выполнении поставленной задачи.

При моделировании деятельности человека-оператора целесообразно использовать такие временные характеристики деятельности как математическое ожидание $M(T)$ и дисперсию $D(T)$ времени выполнения структурной единицы деятельности.

В качестве предельного закона распределения случайной величины - времени, затрачиваемого на выполнение единицы деятельности, может быть принято гамма-распределение [18, 19], плотность распределения которого имеет вид

$$
f(t)=\left\{\begin{array}{l}
0 \text { nрu } \quad t<0 ; \\
\frac{\beta^{\alpha}}{\Gamma(\alpha)} * t^{\alpha-1} * e^{-\beta t} \quad \text { npu } t>0 .
\end{array}\right.
$$

где $\alpha$ - параметр, определяющий форму кривой распределения; $\beta$ - масштабный параметр. 
Параметры распределения выражаются как

$$
\alpha=\frac{M^{2}(T)}{D(T)} ; \beta=\frac{M(T)}{D(T)} .
$$

При больших значениях $\alpha(\alpha>10 \ldots 12)$ в качестве предельного закона распределения времени, затрачиваемого на выполнение единицы деятельности, можно брать нормальный закон.

Для функционального контроля временные характеристики определяются следующим образом [1]

$$
M\left(T_{\phi к}\right)=M\left(T_{к о}\right)+M\left(T_{\text {ла }}\right), \quad D\left(T_{\phi \kappa}\right)=D\left(T_{\kappa о}\right)+D\left(T_{\text {ла }}\right),
$$

где $T_{к о}$ - время выполнения контрольной операции; $T_{\text {ла }}$ - время выполнения операции логического анализа результатов контроля.

Аналогично определяются временные характеристики функциональной единицы диагностический контроль.

В качестве надежностных характеристик целесообразно использовать показатели вероятности безошибочного и ошибочного выполнения операции.

Блок 6. Представить структуру деятельности на уровне операционных единиц, для которых могут быть заданы количественные характеристики качества их выполнения.

В качестве операционных единиц деятельности понимается элементарное действие как отдельный психофизиологический акт, который как нечто цельное реализуется человеком в его деятельности [20-22]. Такими единицами (элементарными действиями) являются восприятие или извлечение из памяти образов, понятий, суждений, а также простые моторные действия имеющие законченность в деятельности оператора.

Элементарные действия могут быть следующих типов [23]:

- эффекторные действия, включающие моторные и речевые (стандартные голосовые команды и сообщения) действия;

- информационные действия, включающие афферентные (восприятие) и мнемические (актуализация, внутренний информационный поиск, воспоминание) действия, логические действия (выбор из нескольких альтернатив), внешний информационный поиск (перенос взора).

Понятие «элементарное действие» относительно и зависит от особенностей системы. Критерием элементарного действия является его неделимость на более мелкие элементы, имеющие практический смысл, а также способность оператора выполнять его как единый, целостный акт [24].

Блок 7. Определить показатели КДО для каждой операционной единицы с помощью:

- специальных справочных данных;

- сопоставления результатов эксплуатации аналогичных ЭС;

- $\quad$ проведения специальных экспериментов

Показатели КДО для ОЕ классифицируются на надежностные и временные. Формульные 
зависимости для расчета отдельных характеристик представлены в [1, 8, 11, 18].

Блок 8. Через известные характеристики ОЕ вычисляют показатели КДО на уровне программных единиц, то есть расчет показателей КДО производится «снизу вверх»: на основе показателей КДО при выполнении ОЕ вычисляют показатели выполнения функциональных единиц, которые в свою очередь, являются основой для определения интегрального показателя КДО для ПЕ.

\section{Автоматизация расчета оценки показателей качества деятельности оператора на уровне операционных единиц}

Преимущество структурного метода А.И.Губинского заключается в структурировании деятельности, выделении и анализе ее основных элементов. СМ отличается «аналитичностью» и в принципе является чисто расчетным.

Для применения этого метода на электронно-вычислительных машинах (ЭВМ) и автоматизированного оценивания качества деятельности оператора наибольшую сложность представляет оценка показателей КДО на уровне операционных единиц.

Исходными данными для решения задачи является алгоритм выполнения операции, доведенный до уровня функциональных единиц (ФЕ). Задачей ЭВМ является выполнение самой трудоемкой части метода:

- анализ характера функциональной единицы;

- декомпозиция до уровня операционных единиц;

- оценивание показателей КДО при выполнении операционных единиц;

- свертка рассчитанных показателей КДО до уровня функциональных единиц;

- свертка показателей КДО до уровня программной единицы деятельности.

Для решения данных задач целесообразно использовать понятие рабочего места оператора. Рабочее место - пространство в ЭС, оснащенное средствами отображения информации, органами управления и вспомогательными устройствами, необходимыми для осуществления профессиональной деятельности человеком-оператором [25]. Будем понимать под рабочим местом пространство одного оператора в связи с ограниченностью пространства в современных образцах ЭС. Определим систему координат для каждого рабочего места (рис. 3).

Таким образом, автоматизированное решение поставленной задачи можно представить в виде нескольких этапов (для простоты примера рассмотрим анализ деятельности одного оператора с целью получения временных характеристик деятельности, для наглядности представления данных будем использовать операторы языка программирования Pascal).

Первый этап - описание в качестве исходных данных алгоритма выполнения задачи в виде последовательности функциональных единиц деятельности, характеристик рабочего места оператора и антропометрических характеристик оператора. 

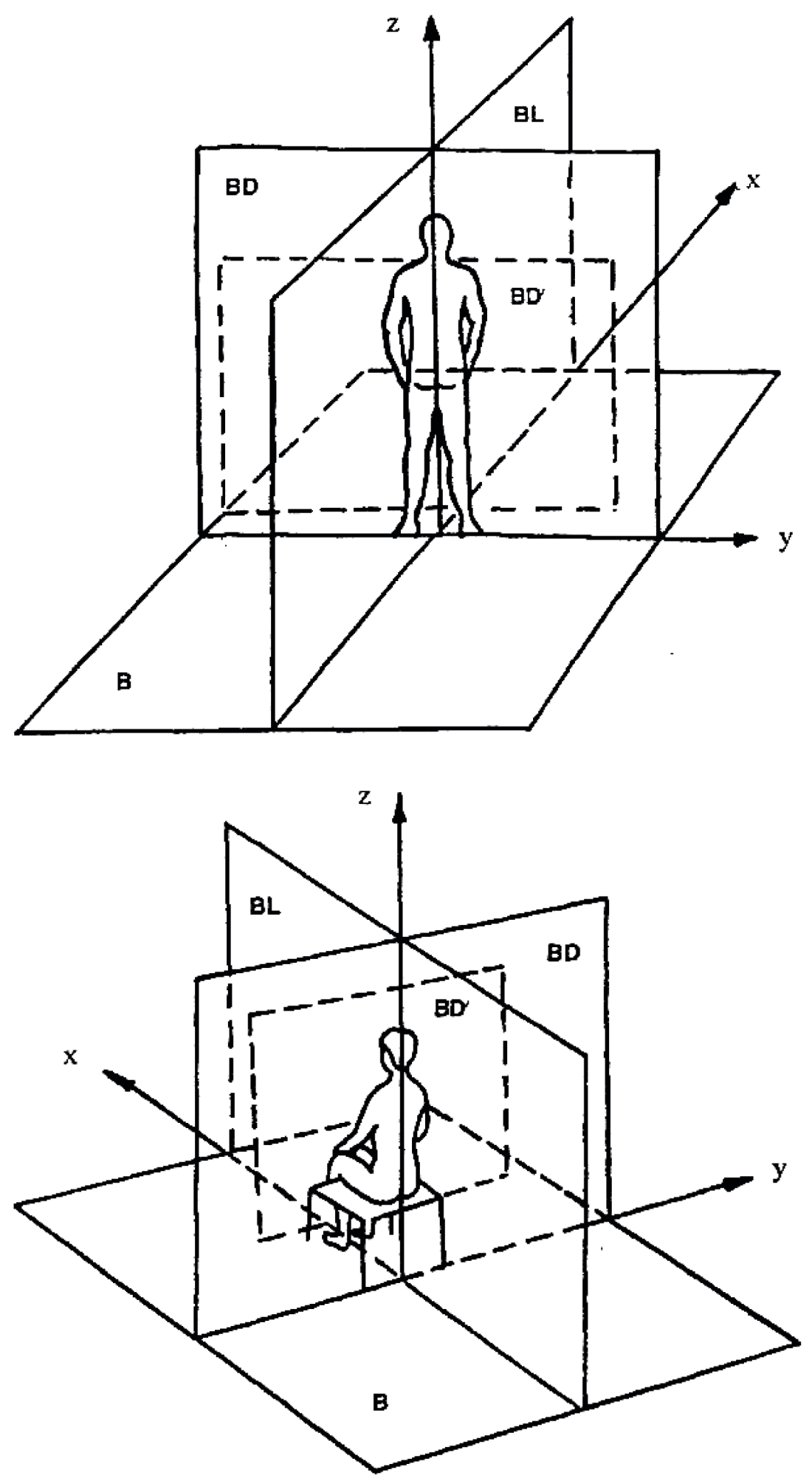

Рисунок 3. 
Системы отсчета, используемые при расчетах параметров рабочих мест для работы в положении стоя и сидя ( $B$ - горизонтальная плоскость (пол или другая опорная поверхность); $B D$ - вертикальная плоскость (фронтальная), касательная к выступающим точкам спины; $B D^{\prime}$ - вертикальная плоскость (фронтальная), касательная к переднему краю оборудования; $B L$ - серединно-сагиттальная плоскость).

Рассмотрим каждую единицу деятельности как структуру данных следующего содержания

$$
\begin{aligned}
& \text { Type } \\
& \text { tEdDeyat }=\text { structure } \\
& \text { FD : boolean; } \\
& P R: \text { pointer; } \\
& M: \text { real; } \\
& D: \text { real }
\end{aligned}
$$

end;

где $F D$ - признак возможности (целесообразности) декомпозиции до единиц нижнего уровня иерархии (при $F D=$ true декомпозиция должна проводиться, в противном случае её применение нецелесообразно); $P R$ - указатель на элементы рабочего места оператора ЭС взаимодействие с которыми осуществляется при выполнении данной единицы; $M$ математическое ожидание времени выполнения этой единицы; $D$ - дисперсию времени выполнения единицы деятельности.

Таким образом, переменные для программной единицы устанавливаются как

$$
F D=\text { true } P R=0 ; M=0 ; D=0 .
$$

Для функциональной единицы как

$$
F D=\text { true } P R=k ; M=0 ; D=0,
$$

если используется декомпозиция до операционных единиц или

$$
F D=\text { false; } P R=k ; M=m ; D=d,
$$

если декомпозиция нецелесообразна. Соответственно, для операционной единицы

$$
F D=\text { false } P R=k ; M=m ; D=d,
$$

где $k$ - указатель на элемент рабочего места из диапазона $1 . . N(N$ - количество объектов управления на рабочем месте); $m, d$ - временные характеристики деятельности, определенные экспериментально или на основе других методик.

Таким образом, структуру данных - алгоритм деятельности можно представить как Var

Algoritm: array[0..L] of tEdDeyat;

где $L$ - количество функциональных единиц в программной единице; Algoritm[1].. 
Algoritm[L] - характеристики функциональных единиц; Algoritm[0] - характеристики программной единицы.

Рабочее место оператора можно представить как совокупность объектов управления

$$
R M=\operatorname{array}[1 . . N] \text { of tObjectUpr; }
$$

где $N$ - количество объектов управления на рабочем месте.

Каждый объект управления (орган управления, вспомогательное устройство и средство отображения информации) определяется как следующая структура данных:

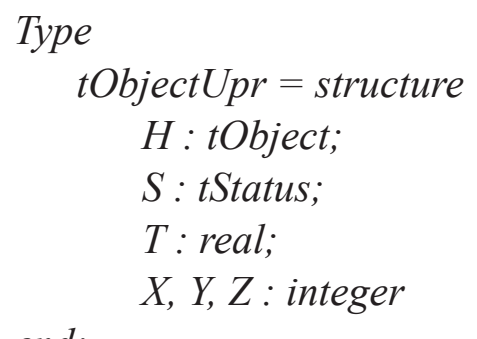

end;

где $H$ - тип элемента (тумблер, кнопка, индикатор и так далее); $S$ - состояние (включен/ выключен, нажат/отжат, значение из диапазона); $T$ - время взаимодействия оператора с объектом (усредненное время нажатия на кнопку, переключения тумблера и так далее); $X, Y, Z$ - координаты $X, Y, Z$ в указанной системе координат рабочего места (считаем орган управления точечным).

Аналогично, используя знания о типичной организации рабочего места ЭС, можем описать в той же системе координат оператора

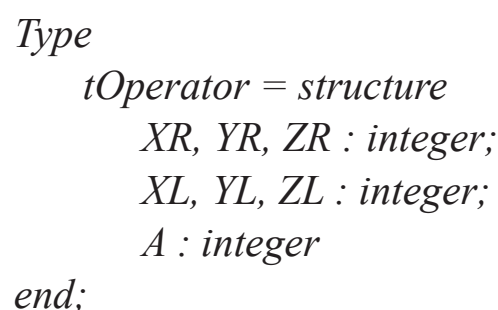

где $X R, Y R, Z R$ - координаты кисти правой руки; $X L, Y L, Z L$ - координаты кисти левой руки; $A$ - угол поворота головы по горизонтали.

Считаем, таким образом, что управление производится только руками (например, рабочее место оператора-водителя) и органы управления, вспомогательные устройства и средства отображения информации расположены на уровне глаз оператора, не требуя поворота головы по вертикали или поворота туловища (например, рабочее место оператора-наводчика).

Второй этап: проведение декомпозиции до уровня операционных единиц с одновременной сверткой показателей быстродействия 
For $k:=1$ to $L$ do

begin

if Algoritm[k].FD

then

Decomposition(Algoritm $[k]$ );

Calc(Algoritm $[k])$

end;

где Decomposition(..) - подпрограмма декомпозиции $k$-й функциональной единицы на операционные; Calc(..) - подпрограмма вычисления суммарного времени выполнения алгоритма.

Третий этап: декомпозиция функциональных единиц на операционные единицы проводится на основе известных в эргономике данных, отличающихся друг от друга детальностью и подробностью подхода. В качестве простейшего варианта можно рассмотреть следующую совокупность операционных единиц как результат декомпозиции функциональной единицы «переключения тумблера»:

- поиск (перенос взора и перенос руки);

- восприятие переключателя;

- выполнение операции переключения.

Длительность информационного поиска и восприятия объекта управления можно определить из широко представленных в литературе экспериментальных данных [1, 2, $5,6,7,8,9]$, либо на основе собственных вычислений.

Зная координаты объекта и положение оператора в пространстве легко определить необходимость и рассчитать показатели длительности переноса взгляда, движения рук, поворота головы и так далее.

Так, например, время движения правой руки к объекту управления можно описать формулой

$$
t_{\Pi P}=\frac{\sqrt{(X R-X)^{2}+(Y R-Y)^{2}+(Z R-Z)^{2}}}{V_{C P}}
$$

где $V_{C P}$ - средняя скорость движения руки (из табличных данных).

Выполнение операции переключения определяется переменной Тструктуры данных объекта управления.

Временные характеристики выполнения функциональной единицы заносятся в переменные Algoritm[k].M и Algoritm[k].D.

Положение оператора после выполнения функциональной единицы определяется координатами задействованного органа управления. 
Реализованная программная система априорного оценивания показателей качества деятельности операторов ЭС на основе структурного метода позволяет определить минимально допустимое время выполнения оператором (экипажем) программной единицы деятельности, важное для получения оценки потенциальной эффективности ЭС в любых условиях ее эксплуатации.

\section{Библиография :}

1. Шибанов Г.П. Количественная оценка деятельности человека в системах человек-техника. М.: Машиностроение, 1983.- 263 с.

2. Бондаренко А.Г., Харитонов В.В., Соловей Ю.Н. Эргономическая оптимизация обучающей среды при подготовке авиационных специалистов с использованием компьютерных систем // Тренды и управление. 2015. №3. С. 301-317.

3. Богомолов А.В., Кукушкин Ю.А. Концептуальные основы математического обеспечения обработки информации о функциональных состояниях операторов в инженерно-психологических и эргономических исследованиях // Развитие психологии в системе комплексного человекознания: часть 2 / Отв. ред. А. Л. Журавлев, В. А. Кольцова.-М.: Изд-во Института психологии РАН, 2012. С. 415-417.

4. Петухов И.В. модель и система оценки успешности операторской деятельности в человеко-машинных системах управления // Научно-технический вестник Поволжья. 2011. № 3. С. 156-162.

5. Лукаш А.А., Димитриев Ю.В., Житников А.Г. Методы эргономического обеспечения разработки систем управления эргатических комплексов // Тренды и управление. 2015. № 2. С. 154-161.

6. Богомолов А.В., Кукушкин Ю.А.,Пономаренко А.В., КозловскийЭ.А. Методическое обеспечениеисследования нервно-эмоционального напряжения и резервов внимания оператора в процессе тренажерной подготовки // Актуальные проблемы психологии труда, инженерной психологии и эргономики. Выпуск 5 / Под ред. А.А.0бознова, А.Л.Журавлева. М.: Издательство Института психологии РАН, 2013. С. 153-176.

7. Петухов И.В. Исследование сенсорно-моторного взаимодействия человека-оператора и технической системы // Мехатроника, автоматизация, управление. 2012. № 2. С. 33-37.

8. Губинский А.И., Евграфов В.Г. Эргономическое проектирование судовых систем управления. Л.: Судостроение, 1977. - 224 с.

9. Климов Р.С., Лопота А.В., Спасский Б.А. Тенденции развития наземных робототехнических систем военного назначения//Робототехника и техническая кибернетика. 2015. № 3 (8). С. 3-10.

10. Хрипунов С.П., Чиров Д.С., Благодарящев И.В. Военная робототехника: современные тренды и векторы развития // Тренды и управление. 2015. № 4. С. 410-422.

11. Фрумкин А.А., Зинченко Т.П., Винокуров Л.В. Методы и средства эргономического обеспечения проектирования. СПб.: ПГУПС, 1999.- 179 с. 
12. Гузий А.Г., Кукушкин Ю.А., Богомолов А.В. Методология стабилизации функционального состояния оператора системы «человек-машина» // Мехатроника, автоматизация, управление. 2002. № 5. С. 9.

13. Кукушкин Ю.А., Богомолов А.В. Методы обработки информации в задачах диагностики функциональных состояний оператора // Актуальные проблемы психологии труда, инженерной психологии и эргономики. Выпуск 3 / Под. ред. В.А. Бодрова, А.Л. Журавлева. М.: Издательство Института психологии РАН, 2012. C. 316-336.

14. Чаусов Д.Н., Петухов И.В., Беляев В.В., Богачев К.А., Курасов П.А. программно-аппаратный комплекс оценки эффективности деятельности операторов // Вестник Московского государственного областного университета. Серия: Физика-математика. 2014. № 2. С. 80-86.

15. Суходольский Г.В. Структурно-алгоритмический анализ и синтез деятельности. Л.: ЛГУ, 1976. 120 с.

16. Никифоров Д.А., Ворона А.А., Богомолов А.В., Кукушкин Ю.А. Методика оценивания потенциальной ненадежности действий летчика // Безопасность жизнедеятельности. 2015. № 7 (175). С. 7-16.

17. Кукушкин Ю.А., Богомолов А.В., Ушаков И.Б. Математическое обеспечение оценивания состояния материальных систем. Информационные технологии. 2004. № 7 (приложение). 32 с.

18. Введение в эргономику / Под ред. В.П.Зинченко. М.: Советское радио, 1974. 352 с.

19. Богомолов А.В. Концепция математического обеспечения диагностики состояния человека // Информатика и системы управления. 2008. № 2 (16). С. 11-13.

20. Вопросы инженерной психологии в автоматизированных системах управления / под ред. Сафаряна С.Н. Л.: ЛГУ, 1972. 144 с.

21. Ушаков И.Б., Богомолов А.В., Кукушкин Ю.А. Методологические аспекты динамического контроля функциональных состояний операторов опасных профессий // Медико-биологические и социальнопсихологические проблемы безопасности в чрезвычайных ситуациях. 2010. №4-2. С. 6-12.

22. Венда В.Ф. Инженерная психология и синтез систем отображения информации. М.: Машиностроение, 1982. 344 C.

23. Зараковский Г.М., Павлов В.В. Закономерности функционирования эргатических систем.- М.: Радио и Связь, 1987. 232 c.

24. Справочник по инженерной психологии / Под ред. Б.Ф.Ломова. М.: Машиностроение, 1982.386 с.

25. Фокин Ю.Г. Военная эргономика. Вопросы технического обеспечения операторской деятельности. Выпуск 1. М.: Изд. МО СССР, 1976. 200 с.

\section{References:}

1. Shibanov G.P. Kolichestvennaya otsenka deyatel'nosti cheloveka v sistemakh chelovek-tekhnika. M.: Mashinostroenie, 1983.- $263 \mathrm{~s}$.

2. Bondarenko A.G., Kharitonov V.V., Solovei Yu.N. Ergonomicheskaya optimizatsiya obuchayushchei sredy pri podgotovke aviatsionnykh spetsialistov s ispol'zovaniem komp'yuternykh sistem // Trendy i upravlenie. 2015. №3. c. 301-317. 
3. Bogomolov A.V., Kukushkin Yu.A. Kontseptual'nye osnovy matematicheskogo obespecheniya obrabotki informatsii o funktsional'nykh sostoyaniyakh operatorov v inzhenerno-psikhologicheskikh i ergonomicheskikh issledovaniyakh // Razvitie psikhologii v sisteme kompleksnogo chelovekoznaniya: chast' 2 / Otv. red. A. L. Zhuravlev, V. A. Kol'tsova.-M.: Izd-vo Instituta psikhologii RAN, 2012. S. 415-417.

4. Petukhov I.V. model' i sistema otsenki uspeshnosti operatorskoi deyatel'nosti v cheloveko-mashinnykh sistemakh upravleniya // Nauchno-tekhnicheskii vestnik Povolzh'ya. 2011. № 3. S. 156-162.

5. Lukash A.A., Dimitriev Yu.V., Zhitnikov A.G. Metody ergonomicheskogo obespecheniya razrabotki sistem upravleniya ergaticheskikh kompleksov // Trendy i upravlenie. 2015. № 2. S. 154-161.

6. Bogomolov A.V., Kukushkin Yu.A., Ponomarenko A.V., Kozlovskii E.A. Metodicheskoe obespechenie issledovaniya nervno-emotsional'nogo napryazheniya i rezervov vnimaniya operatora $v$ protsesse trenazhernoi podgotovki // Aktual'nye problemy psikhologii truda, inzhenernoi psikhologii i ergonomiki. Vypusk 5 / Pod red. A.A.Oboznova, A.L.Zhuravleva. M.: Izdatel'stvo Instituta psikhologii RAN, 2013. S. 153-176.

7. Petukhov I.V. Issledovanie sensorno-motornogo vzaimodeistviya cheloveka-operatora i tekhnicheskoi sistemy // Mekhatronika, avtomatizatsiya, upravlenie. 2012. № 2. S. 33-37.

8. Gubinskii A.l., Evgrafov V.G. Ergonomicheskoe proektirovanie sudovykh sistem upravleniya. L.: Sudostroenie, 1977. $-224 \mathrm{~s}$.

9. Klimov R.S., Lopota A.V., Spasskii B.A. Tendentsii razvitiya nazemnykh robototekhnicheskikh sistem voennogo naznacheniya//Robototekhnika i tekhnicheskaya kibernetika. 2015. № 3 (8). S. 3-10.

10. Khripunov S.P., Chirov D.S., Blagodaryashchev I.V. Voennaya robototekhnika: sovremennye trendy i vektory razvitiya // Trendy i upravlenie. 2015. № 4. S. 410-422.

11. Frumkin A.A., Zinchenko T.P., Vinokurov L.V. Metody i sredstva ergonomicheskogo obespecheniya proektirovaniya. SPb.: PGUPS, 1999.- $179 \mathrm{~s}$.

12. Guzii A.G., Kukushkin Yu.A., Bogomolov A.V. Metodologiya stabilizatsii funktsional'nogo sostoyaniya operatora sistemy «chelovek-mashina» // Mekhatronika, avtomatizatsiya, upravlenie. 2002. № 5. S. 9.

13. Kukushkin Yu.A., Bogomolov A.V. Metody obrabotki informatsii v zadachakh diagnostiki funktsional'nykh sostoyanii operatora // Aktual'nye problemy psikhologii truda, inzhenernoi psikhologii i ergonomiki. Vypusk 3 / Pod. red. V.A. Bodrova, A.L. Zhuravleva. M.: Izdatel'stvo Instituta psikhologii RAN, 2012. S. 316-336.

14. Chausov D.N., Petukhov I.V., Belyaev V.V., Bogachev K.A., Kurasov P.A. programmno-apparatnyi kompleks otsenki effektivnosti deyatel'nosti operatorov // Vestnik Moskovskogo gosudarstvennogo oblastnogo universiteta. Seriya: Fizika-matematika. 2014. № 2. S. 80-86.

15. Sukhodol'skii G.V. Strukturno-algoritmicheskii analiz i sintez deyatel'nosti. L.: LGU, 1976. 120 s.

16. Nikiforov D.A., Vorona A.A., Bogomolov A.V., Kukushkin Yu.A. Metodika otsenivaniya potentsial'noi nenadezhnosti deistvii letchika // Bezopasnost'zhiznedeyatel'nosti. 2015. № 7 (175). S. 7-16.

17. Kukushkin Yu.A., Bogomolov A.V., Ushakov I.B. Matematicheskoe obespechenie otsenivaniya sostoyaniya material'nykh sistem. Informatsionnye tekhnologii. 2004. № 7 (prilozhenie). $32 \mathrm{s.}$

18. Vvedenie v ergonomiku / Pod red. V.P.Zinchenko. M.: Sovetskoe radio, 1974. 352 s.

19. Bogomolov A.V. Kontseptsiya matematicheskogo obespecheniya diagnostiki sostoyaniya cheloveka // Informatika i sistemy upravleniya. 2008. № 2 (16). S. 11-13. 
20. Voprosy inzhenernoi psikhologii v avtomatizirovannykh sistemakh upravleniya / pod red. Safaryana S.N. L.: LGU, 1972. $144 \mathrm{~s}$.

21. Ushakov I.B., Bogomolov A.V., Kukushkin Yu.A. Metodologicheskie aspekty dinamicheskogo kontrolya funktsional'nykh sostoyanii operatorov opasnykh professii // Mediko-biologicheskie i sotsial'no-psikhologicheskie problemy bezopasnosti v chrezvychainykh situatsiyakh. 2010. № 4-2. S. 6-12.

22. Venda V.F. Inzhenernaya psikhologiya i sintez sistem otobrazheniya informatsii. M.: Mashinostroenie, 1982. $344 \mathrm{s.}$

23. Zarakovskii G.M., Pavlov V.V. Zakonomernosti funktsionirovaniya ergaticheskikh sistem.- M.: Radio i svyaz', 1987.232s.

24. Spravochnik po inzhenernoi psikhologii / Pod red. B.F.Lomova. M.: Mashinostroenie, 1982. $386 \mathrm{s.}$

25. Fokin Yu.G. Voennaya ergonomika. Voprosy tekhnicheskogo obespecheniya operatorskoi deyatel'nosti. Vypusk 1. M.: Izd. MOSSSR, 1976. 200 s. 